\title{
Dietary protein intake affects expression of genes for lipid metabolism in porcine skeletal muscle in a genotype-dependent manner
}

\author{
Yingying Liu ${ }^{1,2,3} \dagger$, Fengna $\mathrm{Li}^{1} \dagger$, Lingyun $\mathrm{He}^{1,4}$, Bie Tan $^{1}$, Jinping Deng ${ }^{4}$, Xiangfeng Kong ${ }^{1 *}$, Yinghui $\mathrm{Li}^{1,3}$, \\ Meimei Geng ${ }^{1}$, Yulong Yin ${ }^{1,5 *}$ and Guoyao Wu ${ }^{1,6}$ \\ ${ }^{1}$ Key Laboratory of Agro-Ecological Processes in Subtropical Region, Hunan Provincial Engineering Research Centre of \\ Healthy Livestock and Poultry, Scientific Observing and Experimental Station of Animal Nutrition and Feed Science in \\ South-Central, Ministry of Agriculture, Institute of Subtropical Agriculture, Chinese Academy of Sciences, Changsha, \\ Hunan 410125, People's Republic of China \\ ${ }^{2}$ Hunan Animal Science and Veterinary Medicine Research Institute, Changsha, Hunan 410131, People's Republic of China \\ ${ }^{3}$ College of Animal Science and Technology, Hunan Agricultural University, Changsha, Hunan 410128, \\ People's Republic of China \\ ${ }^{4}$ University of Chinese Academy of Sciences, Beijing 100049, People's Republic of China \\ ${ }^{5}$ Southwest Collaborative Innovation Center of Swine for Quality and Safety, 211 Huiming Road, Wenjiang District, \\ Chengdu, People's Republic of China \\ ${ }^{6}$ Department of Animal Science and Faculty of Nutrition, Texas A\&M University, College Station, TX 77843, USA
}

(Submitted 3 August 2014 - Final revision received 24 November 2014 - Accepted 2 December 2014 - First published online 16 March 2015)

\section{Abstract}

Skeletal muscle is a major site for the oxidation of fatty acids (FA) in mammals, including humans. Using a swine model, we tested the hypothesis that dietary protein intake regulates the expression of key genes for lipid metabolism in skeletal muscle. A total of ninetysix barrows (forty-eight pure-bred Bama mini-pigs (fatty genotype) and forty-eight Landrace pigs (lean genotype)) were fed from 5 weeks of age to market weight. Pigs of fatty or lean genotype were randomly assigned to one of two dietary treatments (low- or adequate-protein diet), with twenty-four individually fed pigs per treatment. Our data showed that dietary protein levels affected the expression of genes involved in the anabolism and catabolism of lipids in the longissimus dorsi and biceps femoris muscles in a genotype-dependent manner. Specifically, Bama mini-pigs had more intramuscular fat, SFA and MUFA, as well as elevated mRNA expression levels of lipogenic genes, compared with Landrace pigs. In contrast, Bama mini-pigs had lower mRNA expression levels of lipolytic genes than Landrace pigs fed an adequate-protein diet in the growing phase. These data are consistent with higher white-fat deposition in Bama mini-pigs than in Landrace pigs. In conclusion, adequate provision of dietary protein (amino acids) plays an important role in regulating the expression of key lipogenic genes, and the growth of white adipose tissue, in a genotype- and tissue-specific manner. These findings have important implications for developing novel dietary strategies in pig production.

Key words: Bama mini-pigs: Dietary protein: Gene expression: Lipid metabolism

Adequate provision of protein in diets may play an important role in regulating the expression of genes involved in lipid metabolism ${ }^{(1,2)}$. To our knowledge, there are few published studies in this research area. Fat and fatty acids (FA), in either adipose tissue or skeletal muscle, contribute importantly to various aspects of meat quality, and are central to the nutritional value of meat ${ }^{(3,4)}$. Early work on meat FA composition focused on adipose tissue, where the bulk of the body's FA was stored. In recent years, there has been more emphasis on muscle because of its significance as a nutritious food ${ }^{(5)}$.

Skeletal muscle is a complex tissue and has considerable plasticity in its response to dietary intakes of protein and energy. Intramuscular fat (IMF, often termed marbling fat),

Abbreviations: ACC $\alpha$, acetyl-CoA carboxylase $\alpha$; BF, biceps femoris; BW, body weight; FA, fatty acids; FABP, fatty acid binding protein; FAS, fatty acid synthase; FATP, fatty acid transport proteins; GAPDH, glyceraldehyde-3-phosphate dehydrogenase; GB diet, Chinese conventional diet; HSL, hormonesensitive lipase; IMF, intramuscular fat; LD, longissimus dorsi; LPL, lipoprotein lipase; NRC diet, National Research Council diet; PGC-1 $\alpha$, PPAR $\gamma$ coactivator- $1 \alpha$.

* Corresponding authors: Dr X. Kong, fax +86 731 84612685, email nnkxf@isa.ac.cn; Dr Y. Yin, fax +86 73184612685 , email yinyulong@isa.ac.cn 
Table 1. Animals and treatments

\begin{tabular}{|c|c|c|c|c|c|c|}
\hline \multirow{2}{*}{$\frac{\text { Types... }}{\text { Items }}$} & \multicolumn{3}{|c|}{ Landrace pig } & \multicolumn{3}{|c|}{ Bama mini-pig } \\
\hline & Body weight $(\mathrm{kg})$ & GB diet group & NRC diet group & Body weight $(\mathrm{kg})$ & GB diet group & NRC diet group \\
\hline Phase 1 & $7-20$ & GB diet 1 & NRC diet 1 & $3-15$ & GB diet 1 & NRC diet 1 \\
\hline Phase 2 & $20-50$ & GB diet 2 & NRC diet 2 & $15-35$ & GB diet 2 & NRC diet 2 \\
\hline Phase 3 & $50-90$ & GB diet 3 & NRC diet 3 & $35-55$ & GB diet 3 & NRC diet 3 \\
\hline
\end{tabular}

GB diet, Chinese conventional diet; NRC diet, National Research Council diet.

which is the total lipid within the skeletal muscle, has a role in the tenderness and juiciness of cooked meat ${ }^{(6-10)}$. The role of marbling fat is of particular interest in pigs because genetic selection for lean pigs has reduced the level of marbling fat to below $1 \%$ of muscle weight in modern pigs, compared with $2-4 \%$ in US studies in the 1960s. However, in humans and farm animals, excess accumulation of IMF in muscle tissues is associated with conditions such as insulin resistance and type 2 diabetes. Therefore, many intrinsic pathways in both intramuscular adipocytes and myofibres could provide an explanation for the variability of IMF content, such as the balance between lipid anabolic and catabolic pathways, intracellular trafficking of FA and myofibre energetic metabolism in skeletal muscle.

Feeding strategies could change several aspects of meat quality other than eating quality, through the effect on muscle: fat ratio and composition, although the underlying mechanisms have not been elucidated. There is increasing evidence for roles of dietary protein in influencing growth and body composition of aquatic livestock ${ }^{(11)}$ and human subjects ${ }^{(12)}$. For example, dietary protein:energy ratio is negatively correlated with fat deposition in the carcass. Likewise, when the diet provides an ideal level of crude protein $(95 \mathrm{~g} / \mathrm{kg} \mathrm{DM})$, protein deposition in growing pigs reaches a maximum value of $71 \mathrm{~g} / \mathrm{d}^{(13)}$. The use of low-protein diets to increase marbling fat in pigs has resulted in a higher score for tenderness and juiciness in cooked pork. Several studies have shown that IMF content can be increased by feeding pigs a protein/ lysine-deficient diet in the growing or finishing phase. In the study of Teye et al. ${ }^{(14)}$, amounts of total lipids in the longissimus dorsi (LD) muscle were $2 \cdot 8 \%$ when pigs were fed an $18 \%$ crude protein diet, compared with $1.7 \%$ fat in a standard diet containing $20 \%$ protein. The scores for tenderness and juiciness (range 1-8) were markedly increased from 4.2 and 3.9 in the $20 \%$ protein diet to 4.8 and 4.4 in the $18 \%$ protein diet, respectively.

Bama mini-pigs (Sus scrofa domestica), a Chinese indigenous mini-pig breed located in Bama County, Guangxi
Province of China, is a useful animal model for studying lipid metabolism ${ }^{(15)}$ and high-quality meat. Landrace pigs, a representative lean genotype, have a fast growing rate and more meat to yield commercial benefits. Although these two breeds show obvious differences in muscle growth and meat quality, how dietary nutrients mediate the effect of breed on lipid metabolism and its underlying mechanism is still unknown. The purpose of the present study was to determine the effects of dietary nutrient levels on fat deposition, FA composition and lipid metabolism in Bama mini-pigs and Landrace pigs, during various phases of their growth.

\section{Materials and methods}

\section{Animals, diets and treatment}

A total of ninety-six barrows (forty-eight pure-bred Bama mini-pigs (fatty type) ${ }^{(16)}$, average initial body weight (BW) 3.38 (sem 0.96) kg, a Chinese local breed; forty-eight Landrace pigs (lean type), average initial BW 7.68 (sEm 0.89) kg) were fed from 5 weeks of age to market weight. The experiment was a $2 \times 2$ factorial arrangement, with two breeds (Bama mini-pigs $v$. Landrace pigs) and two dietary protein levels (National Research Council diet (NRC diet) $v$. Chinese conventional diet (GB diet)), giving a total of four treatments (Table 1). Piglets from each breed were randomly assigned to one of the two dietary treatments, with twenty-four piglets in each treatment. The NRC diets were formulated to meet the nutrient requirements recommended by the $\mathrm{NRC}^{(17)}$, whereas the GB diets were formulated to meet the recommendations of the Chinese National Feeding Standard for Swine ${ }^{(18)}$, and protein levels of the latter were lower than those of the former (Table 2; online supplementary Table S1). The animals were individually housed in $0.6 \mathrm{~m} \times 1.2 \mathrm{~m}$ pens with hard plastic slatted flooring, and had free access to drinking-water and their respective diets ${ }^{(19)}$. The dietary phase was based on the physiological stage of pigs.

Table 2. Nutrient levels of the experimental diets

\begin{tabular}{|c|c|c|c|c|c|c|}
\hline \multirow{2}{*}{$\frac{\text { Types. . }}{\text { Items }}$} & \multicolumn{3}{|c|}{ NRC diets } & \multicolumn{3}{|c|}{ GB diets } \\
\hline & NRC diet 1 & NRC diet 2 & NRC diet 3 & GB diet 1 & GB diet 2 & GB diet 3 \\
\hline Digestible energy* $(\mathrm{MJ} / \mathrm{kg})$ & $14 \cdot 22$ & $14 \cdot 21$ & $14 \cdot 22$ & $13 \cdot 46$ & 13.40 & $13 \cdot 40$ \\
\hline Crude proteint (\%) & $20 \cdot 06$ & $18 \cdot 01$ & $15 \cdot 11$ & 18.03 & $16 \cdot 05$ & 13.46 \\
\hline
\end{tabular}

NRC diet, National Research Council diet; GB diet, Chinese conventional diet.

* Digestible energy was the calculated value.

† Crude protein was the measured value. 
The experiment was carried out in accordance with the Chinese Guidelines for Animal Welfare and Experimental Protocol, and approved by the Animal Care and Use Committee of the Institute of Subtropical Agriculture, the Chinese Academy of Sciences ${ }^{(20,21)}$.

\section{Sample collection}

BW ranges for the nursery, growing and finishing phases (namely phase 1 , phase 2 and phase 3, respectively) were defined as $7-20,20-50$ and $50-90 \mathrm{~kg}$, respectively, for Landrace pigs; and 3-15, 15-35 and 35-55 kg, respectively, for Bama mini-pigs (Table 1). At the end of each phase, eight pigs from each treatment were randomly selected, weighed, bled and killed. In brief, after fasting for $12 \mathrm{~h}$ and the measurement of pre-slaughter BW, blood samples were collected into $10 \mathrm{ml}$ centrifuge tubes containing sodium heparin (14.3 United States Pharmacopeia (USP) units/ml), and subsequently centrifuged at $900 \mathrm{~g}$ for $10 \mathrm{~min}$ at $4^{\circ} \mathrm{C}$ to recover plasma, and stored at $-80^{\circ} \mathrm{C}$ until biochemical parameter analysis ${ }^{(22-24)}$. The pigs were held under general anaesthesia and killed by a jugular vein injection of $4 \%$ sodium pentobarbital solution $(40 \mathrm{mg} / \mathrm{kg}$ BW). After the head, legs, tail and viscera were removed, the carcass was split longitudinally. Samples of the LD and biceps femoris (BF) muscles on the right-side carcass were collected immediately; visible intermuscular adipose tissue was carefully removed. The samples were snap-frozen in liquid $\mathrm{N}_{2}$, and stored at $-80^{\circ} \mathrm{C}$ for analysis. ${ }^{(25)}$

\section{Determination of carcass characteristics}

Back fat thickness at the tenth rib was measured immediately post-mortem, according to the Chinese Guidelines on Performance Measurement Technology and Regulations for Pigs ${ }^{(26)}$, with the average of measurements at three points: the first rib; last rib; last lumbar vertebra. Each left-side carcass was weighed and then physically dissected into skin, skeletal muscle, fat and bone. Weights of fat and muscle tissues were multiplied by 2 for calculating the percentages of fat and muscle of the whole carcass, respectively.

\section{Intramuscular fat analysis}

Analysis of IMF in different muscle tissues was performed in duplicate according to the Association of Official Analytical Chemists method ${ }^{(27)}$, using the Soxhlet extraction method ${ }^{(28)}$.

\section{Measurements of plasma metabolites}

The concentrations of total cholesterol, TAG, LDL and HDL, and activity of lipase in plasma were measured, using a biochemical analytical instrument (Beckman CX4; Beckman Coulter, Inc.) and commercial kits (Sino-German Beijing Leadman Biotech Limited).

\section{Fatty acid composition analysis}

The percentages of FA in IMF were determined by Agilent 7890A GC. Briefly, lipids were extracted from the LD and BF muscles using chloroform. Methyl esters of lipids were obtained via saponification with a solution of $2 \mathrm{ml}$ hexane, $40 \mu \mathrm{l}$ methyl acetate and $100 \mu \mathrm{l}$ sodium methoxide; the hexane layer was aspirated after vortexing via anhydrous sodium sulphate for the analysis of FA by GC, using a chromatographic column (sp-2560) $(100 \mathrm{~m} \times 250 \mu \mathrm{m} \times 0.2 \mu \mathrm{m})$ (Applied Biosystems). The gas chromatograph programme temperature was as follows: initial column temperature held at $140^{\circ} \mathrm{C}$ for $15 \mathrm{~min}$; increased at a rate of $3^{\circ} \mathrm{C} / \mathrm{min}$ to $240^{\circ} \mathrm{C}$; held for $15 \mathrm{~min}$ at $240^{\circ} \mathrm{C}$. The injector and detector temperatures were set at $250^{\circ} \mathrm{C}$. Hydrogen was used at a flow rate of $30 \mathrm{ml} / \mathrm{min}$, air $400 \mathrm{ml} / \mathrm{min}, \mathrm{N} 40 \mathrm{ml} / \mathrm{min}$ and carrier gas $0.8 \mathrm{ml} / \mathrm{min}$. The inlet temperature was $220^{\circ} \mathrm{C}$, the split ratio was $10: 1$ and the injection volume was $1 \mu \mathrm{l}$. Individual FA peaks were identified by comparison of their retention times with those of the standards (Sigma Chemicals). Results are expressed as g/100 g of total identified $\mathrm{FA}^{(29)}$.

\section{RNA extraction and complementary DNA synthesis}

Total RNA was isolated from the LD and BF tissues using the TRIzol reagent (Invitrogen-Life Technologies), and then treated with DNase I (Invitrogen), according to the manufacturer's instructions ${ }^{(30)}$. RNA quality was checked by $1 \%$ agarose gel electrophoresis, and stained with $10 \mu \mathrm{g} / \mathrm{ml}$ of ethidium bromide. RNA was shown to have an optical density $(\mathrm{OD})_{260}: \mathrm{OD}_{280}$ ratio between 1.8 and $2 \cdot 0$. The first-strand complementary DNA was synthesised with oligo(dT)20 and Superscript II reverse transcriptase (Invitrogen), according to the manufacturers' instructions $^{(31)}$.

\section{Quantitative real-time RT-PCR}

Primers for the selected genes (see online supplementary Table S2) were designed using the Primer 5.0 software. Realtime RT-PCR was performed using the SYBR Green Detection Kit (TaKaRa), containing $\mathrm{MgCl}_{2}$, deoxy-ribonucleoside triphosphate (dNTP) and HotStar Taq polymerase. An aliquot $(2 \mu \mathrm{l})$ of a complementary DNA template (corresponding to $25 \mathrm{ng}$ of total RNA) solution was added to a total volume of $10 \mu \mathrm{l}$, containing $5 \mu \mathrm{l}$ SYBR Green mix, $0 \cdot 2 \mu \mathrm{l}$ ROX Reference Dye $(50 \times)$, and $0 \cdot 2 \mu$ l each of forward and reverse primers ${ }^{(32)}$. After a pre-denaturation programme $\left(10 \mathrm{~s}\right.$ at $\left.95^{\circ} \mathrm{C}\right)$, forty cycles of amplification were performed $\left(95^{\circ} \mathrm{C}\right.$ for $10 \mathrm{~s}$ and $60^{\circ} \mathrm{C}$ for $20 \mathrm{~s}$ ), followed by a melting curve programme $(60-$ $99^{\circ} \mathrm{C}$ with a heating rate of $0 \cdot 1^{\circ} \mathrm{C} / \mathrm{s}$ and fluorescence measurement); and the fluorescent signal was detected by the ABI Prism 7900HT (Applied Biosystems). A melting curve was generated for each sample at the end of each run to ensure the purity of the amplified products. The amplification of glyceraldehyde-3-phosphate dehydrogenase $(G A P D H)$ in each sample was used to normalise the mRNA levels of the selected genes. We calculated the relative expression ratio $(R)$ of mRNA by 

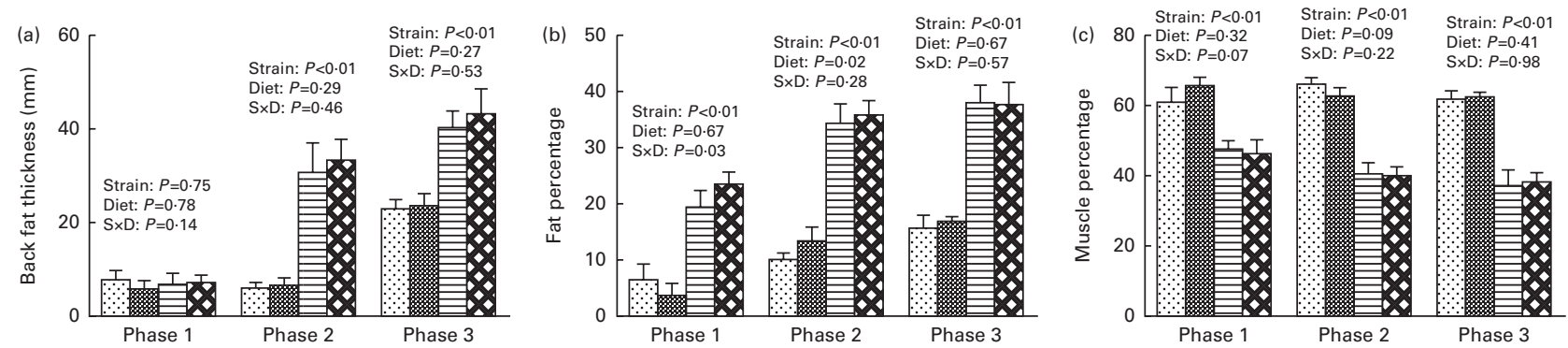

Fig. 1. Effects of dietary protein level and strain on backfat thickness (a), fat mass percentage (b) and muscle mass percentage (c) in growing-finishing pigs.

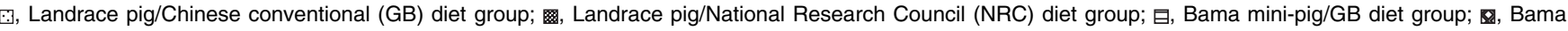
mini-pig/NRC diet group. Values are means $(n 8)$, with their standard errors represented by vertical bars. Effects were considered statistically significant if $P<0.05 . \mathrm{S} \times \mathrm{D}$, strain $\times$ diet interaction.

using the following formula:

$$
R=2^{-\Delta \Delta C_{\mathrm{t}}(\text { sample-control) }},
$$

where $\Delta \Delta C_{\mathrm{t}}$ (sample - control $)=\left(C_{\mathrm{t}}\right.$ gene of interest $-C_{\mathrm{t}}$ GAPDH $)$ for the sample $-\left(C_{\mathrm{t}}\right.$ gene of interest $\left.-C_{\mathrm{t}} \mathrm{GAPDH}\right)$ for the control.

Real-time RT-PCR efficiencies were determined by the amplification of a dilution series of complementary DNA according to the equation $10^{(-1 / \text { slope })}$, as described by Bustin et $a l^{(33)}$, and were consistent between target mRNA and $G A P D H$. Negative controls, in which complementary DNA was replaced by water, were also used in the experiment ${ }^{(34)}$.

\section{Statistical analysis}

Data were analysed by a mixed-effects model using the SAS version 8.2 (SAS Institute, Inc.). Diet, strain and their interactions were included in the statistical model. Effects were considered statistically significant if $P<0 \cdot 05$. Probability values between $0 \cdot 05$ and $0 \cdot 10$ were considered to be trends.

\section{Results}

\section{Total lipid and intramuscular fat}

Back fat thickness and total fat percentage of carcass, and IMF of the LD and BF muscles in Bama mini-pigs were higher $(P<0.05)$, whereas muscle percentage of carcass was lower $(P<0.05)$ than that of Landrace pigs throughout the experiment period (Figs. 1 and 2). The IMF in the BF muscle of

(a)

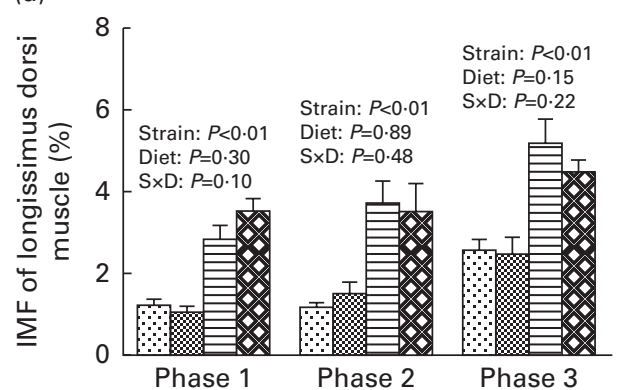

Bama mini-pigs fed the GB diet in phases 1 and 2 were greater $(P<0.05)$ than that of pigs fed the NRC diet, while the IMF in the $\mathrm{BF}$ muscle of Bama mini-pigs fed the GB diet in phase 3 was lower $(P<0.05)$ than that of pigs fed the NRC diet.

\section{Lipid-related substances in plasma}

There was no breed $\times$ diet interaction $(P>0.05)$ for plasma concentrations of total cholesterol, TAG, LDL, HDL, and the activity of lipase (Table 3). Plasma LDL concentration and lipase activity of Bama mini-pigs were higher $(P<0.05)$ than those of Landrace pigs in phase 1 , while they showed no difference in phase 2 or phase 3. Landrace pigs fed the GB diet had higher $(P<0.05)$ TAG concentration in phase 1 , and higher $(P<0.05)$ concentrations of total cholesterol and TAG in phase 2 than those fed the NRC diet.

\section{Fatty acid composition}

As shown in Tables 4 and 5, breed type affected $(P<0.05)$ percentages of FA, especially PUFA, in the LD and BF muscles, as well as the ratio of PUFA:SFA. For the LD muscle (Table 4), Landrace pigs had a higher PUFA percentage in phases 2 and 3 , and a higher PUFA:SFA ratio in phase 2 than Bama minipigs. For the BF muscle (Table 5), Bama mini-pigs had a higher $(P<0.05)$ percentage of MUFA, a lower percentage of PUFA, a lower PUFA:SFA ratio in phase 1 , as well as a higher percentage of SFA and a lower PUFA percentage in phase 3, when compared with Landrace pigs. The PUFA

(b)

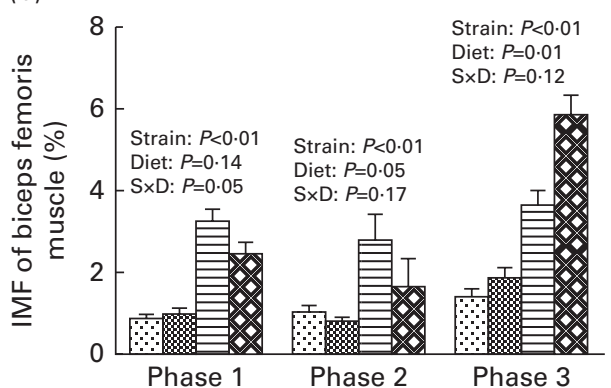

Fig. 2. Effects of dietary protein levels and strains on intramuscular fat (IMF) in the longissimus dorsi (a) and biceps femoris (b) muscles of growing-finishing pigs. [. Landrace pig/Chinese conventional (GB) diet group; 圆, Landrace pig/National Research Council (NRC) diet group; 目, Bama mini-pig/GB diet group; , Bama mini-pig/NRC diet group. Values are means $(n 8)$, with their standard errors represented by vertical bars. Effects were considered statistically significant if $P<0.05$. S $\times \mathrm{D}$, strain $\times$ diet interaction. 
Table 3. Effects of dietary protein levels and strains on the plasma biochemical parameters in growing-finishing pigs (Mean values with their standard errors, $n 8$ )

\begin{tabular}{|c|c|c|c|c|c|c|c|c|}
\hline \multirow[b]{2}{*}{ Items } & \multicolumn{2}{|c|}{ Landrace } & \multicolumn{2}{|c|}{ Bama mini-pig } & \multirow[b]{2}{*}{ SEM } & \multicolumn{3}{|c|}{$P$} \\
\hline & GB diets & NRC diets & GB diets & NRC diets & & Strain & Diet & Strain $\times$ diet \\
\hline \multicolumn{9}{|l|}{ Phase 1} \\
\hline Total cholesterol $(\mathrm{mmol} / \mathrm{l})$ & $2 \cdot 11$ & 1.83 & 2.50 & $2 \cdot 77$ & 0.17 & $<0.01$ & 0.98 & 0.12 \\
\hline $\mathrm{TAG}(\mathrm{mmol} / \mathrm{l})$ & 0.530 & 0.291 & 0.528 & 0.564 & 0.06 & 0.03 & 0.54 & 0.27 \\
\hline $\mathrm{LDL}(\mathrm{mmol} / \mathrm{l})$ & 0.928 & 0.848 & 1.39 & 1.42 & 0.09 & $<0.01$ & 0.78 & 0.53 \\
\hline $\mathrm{HDL}(\mathrm{mmol} / \mathrm{l})$ & 1.06 & 0.883 & 0.990 & 1.16 & 0.10 & 0.30 & 0.97 & 0.09 \\
\hline LPS $(U /)^{*}$ & 26.8 & $27 \cdot 7$ & 33.2 & $37 \cdot 1$ & 1.03 & $<0.01$ & 0.03 & 0.15 \\
\hline \multicolumn{9}{|l|}{ Phase 2} \\
\hline Total cholesterol $(\mathrm{mmol} / \mathrm{l})$ & $2 \cdot 74$ & $1 \cdot 15$ & 3.47 & 3.50 & 0.29 & $<0.01$ & 0.59 & 0.54 \\
\hline TAG $(\mathrm{mmol} / \mathrm{l})$ & $1 \cdot 18$ & 0.805 & 0.602 & 0.814 & 0.08 & 0.16 & 0.83 & 0.07 \\
\hline $\mathrm{LDL}(\mathrm{mmol} / \mathrm{l})$ & 1.47 & 1.34 & 1.66 & 1.67 & 0.14 & 0.13 & 0.70 & 0.69 \\
\hline $\mathrm{HDL}(\mathrm{mmol} / \mathrm{l})$ & 1.43 & 1.40 & 1.03 & 1.07 & 0.13 & 0.02 & 0.99 & 0.80 \\
\hline LPS $(U / I)^{*}$ & $42 \cdot 2$ & $42 \cdot 3$ & $32 \cdot 8$ & 35.8 & 3.08 & 0.02 & 0.64 & 0.67 \\
\hline \multicolumn{9}{|l|}{ Phase 3} \\
\hline Total cholesterol $(\mathrm{mmol} / \mathrm{l})$ & $2 \cdot 66$ & $2 \cdot 61$ & $2 \cdot 88$ & 3.25 & 0.15 & 0.03 & 0.38 & 0.26 \\
\hline TAG (mmol/l) & 0.474 & 0.514 & 0.532 & 0.543 & 0.06 & 0.55 & 0.70 & 0.81 \\
\hline $\operatorname{LDL}\left(\mathrm{mmol} / \mathrm{l}^{\prime}\right.$ & 1.12 & 1.18 & $1 \cdot 17$ & 1.39 & 0.12 & 0.37 & 0.36 & 0.63 \\
\hline $\mathrm{HDL}(\mathrm{mmol} / \mathrm{l})$ & 1.05 & 0.923 & 1.24 & 1.20 & 0.09 & 0.07 & 0.34 & 0.56 \\
\hline LPS $(U / /)^{*}$ & 39.2 & 38.0 & 34.2 & 37.3 & 2.66 & 0.62 & 0.58 & 0.21 \\
\hline
\end{tabular}

GB diet, Chinese conventional diet; NRC, National Research Council diet; LPS, lipase.

* $1 \mathrm{U}$ is defined as the amount of the enzyme that produces a certain amount of enzymatic activity that yields the maximal substrate conversion rate.

percentage of Landrace pigs fed the NRC diet was higher $(P<0.05)$ than that of pigs fed the GB diet, which resulted in an increase in the PUFA:SFA ratio, while its MUFA percentage was lower $(P<0.05)$ than those fed the GB diet.

\section{Expression of fat metabolic-related genes in muscles}

As shown in Figs. 3 and 4, Bama mini-pigs had higher $(P<0.05)$ mRNA levels of acetyl-CoA carboxylase $\alpha(A C C \alpha)$ and PPAR $\gamma$ coactivator- $1 \alpha(P G C-1 \alpha)$ in the LD muscle in phase 3, and of ACC $\alpha$, lipoprotein lipase $(L P L)$ and fatty acid transport protein $1(F A T P-1)$ in the $\mathrm{BF}$ muscle in phase 1 , compared with Landrace pigs. Landrace pigs fed the NRC diet had greater $(P<0.05)$ mRNA levels of hormone-sensitive lipase (HSL) and FATP-1 in the LD muscle in phase 2, higher $(P<0.05)$ mRNA levels of $A C C \alpha, H S L$ and fatty acid-binding protein $4(F A B P-4)$ in the $\mathrm{BF}$ muscle in phase 2 , and lower $(P<0.05)$ mRNA levels of fatty acid synthase $(F A S)$ in the BF muscle in phase 3 than pigs fed the GB diet. Compared with the effects of the NRC diet, Bama mini-pigs fed the GB diet had higher $(P<0.05)$ mRNA levels of $F A S$ in phase 1 and lower $(P<0.05)$ mRNA levels of $F A S$ and $L P L$ in phase 3 in the LD muscle, and higher $(P<0.05)$ mRNA levels of $H S L$ in phase 1 , lower $(P<0.05)$ mRNA levels of $F A S$ in phase 1 , and lower $(P<0.05)$ mRNA levels of $A C C \alpha$ and $P G C-1 \alpha$ in phase 3 in the $\mathrm{BF}$ muscle.

Table 4. Fatty acid percentage in the longissimus dorsi muscle of growing-finishing pigs

(Mean values with their standard errors, $n 8$ )

\begin{tabular}{|c|c|c|c|c|c|c|c|c|}
\hline \multirow[b]{2}{*}{ Items } & \multicolumn{2}{|c|}{ Landrace } & \multicolumn{2}{|c|}{ Bama mini-pig } & \multirow[b]{2}{*}{ SEM } & \multicolumn{3}{|c|}{$P$} \\
\hline & GB diets & NRC diets & GB diets & NRC diets & & Strain & Diet & Strain $\times$ diet \\
\hline \multicolumn{9}{|l|}{ Phase 1} \\
\hline SFA* & $40 \cdot 2$ & $43 \cdot 1$ & 43.2 & $42 \cdot 4$ & $2 \cdot 25$ & 0.63 & 0.68 & 0.45 \\
\hline MUFA† & $42 \cdot 7$ & $32 \cdot 8$ & $41 \cdot 7$ & $50 \cdot 4$ & 3.03 & 0.02 & 0.85 & $<0.01$ \\
\hline PUFA $\ddagger$ & $17 \cdot 1$ & $24 \cdot 1$ & $15 \cdot 0$ & $7 \cdot 25$ & 1.74 & $<0.01$ & 0.84 & $<0.01$ \\
\hline PUFA:SFA ratio & 0.418 & $1 \cdot 18$ & 0.363 & 0.162 & 0.20 & 0.02 & 0.20 & 0.03 \\
\hline \multicolumn{9}{|l|}{ Phase 2} \\
\hline SFA & $40 \cdot 1$ & 41.4 & $51 \cdot 6$ & $44 \cdot 3$ & $2 \cdot 25$ & 0.01 & 0.28 & $0 \cdot 13$ \\
\hline MUFA & $46 \cdot 6$ & $44 \cdot 3$ & 39.9 & $45 \cdot 7$ & $2 \cdot 75$ & 0.43 & 0.61 & 0.24 \\
\hline PUFA & $13 \cdot 3$ & $14 \cdot 3$ & 8.06 & 9.83 & 0.68 & $<0.01$ & $0 \cdot 10$ & 0.66 \\
\hline PUFA:SFA ratio & 0.292 & 0.319 & 0.184 & 0.221 & 0.02 & $<0.01$ & 0.07 & 0.96 \\
\hline \multicolumn{9}{|l|}{ Phase 3} \\
\hline SFA & $46 \cdot 0$ & 38.9 & 45.4 & $44 \cdot 3$ & 2.55 & 0.42 & 0.17 & 0.31 \\
\hline MUFA & $42 \cdot 0$ & $47 \cdot 1$ & $49 \cdot 7$ & $49 \cdot 3$ & 3.00 & 0.16 & 0.49 & 0.42 \\
\hline PUFA & $13 \cdot 9$ & $13 \cdot 6$ & 4.95 & 6.43 & 0.94 & $<0.01$ & 0.59 & 0.41 \\
\hline PUFA:SFA ratio & 0.534 & 0.291 & 0.104 & 0.132 & 0.11 & 0.03 & 0.41 & 0.28 \\
\hline
\end{tabular}

GB diet, Chinese conventional diet; NRC, National Research Council diet.

${ }^{*} \mathrm{SFA}=14: 0+16: 0+18: 0+20: 0$.

†MUFA $=16: 1+18: 1$.

¥PUFA $=18: 2+18: 3+20: 4+20: 5+22: 6$. 
Table 5. Fatty acid percentage in the biceps femoris muscle of growing-finishing pigs

(Mean values with their standard errors, $n$ 8)

\begin{tabular}{|c|c|c|c|c|c|c|c|c|}
\hline \multirow[b]{2}{*}{ Items } & \multicolumn{2}{|c|}{ Landrace } & \multicolumn{2}{|c|}{ Bama mini-pig } & \multirow[b]{2}{*}{ SEM } & \multicolumn{3}{|c|}{$P$} \\
\hline & GB diets & NRC diets & GB diets & NRC diets & & Strain & Diet & Strain $\times$ diet \\
\hline \multicolumn{9}{|l|}{ Phase 1} \\
\hline SFA* & $40 \cdot 6$ & $39 \cdot 1$ & $36 \cdot 7$ & $39 \cdot 9$ & 2.54 & 0.54 & 0.75 & 0.37 \\
\hline MUFA† & $33 \cdot 1$ & $31 \cdot 6$ & $46 \cdot 5$ & $46 \cdot 6$ & $2 \cdot 95$ & $<0.01$ & $0 \cdot 81$ & 0.78 \\
\hline PUFA & $26 \cdot 2$ & $29 \cdot 3$ & $16 \cdot 8$ & $13 \cdot 5$ & $2 \cdot 69$ & $<0.01$ & 0.97 & 0.25 \\
\hline PUFA:SFA ratio & 0.823 & 1.08 & 0.382 & 0.313 & 0.13 & $<0.01$ & 0.48 & 0.22 \\
\hline \multicolumn{9}{|l|}{ Phase 2} \\
\hline SFA & 39.9 & $40 \cdot 4$ & $41 \cdot 6$ & $40 \cdot 6$ & 0.70 & $0 \cdot 22$ & 0.74 & 0.29 \\
\hline MUFA & $43 \cdot 1$ & $35 \cdot 0$ & $45 \cdot 9$ & $45 \cdot 0$ & 1.63 & $<0.01$ & 0.02 & 0.05 \\
\hline PUFA & $17 \cdot 1$ & 24.5 & $13 \cdot 1$ & 14.5 & 1.68 & $<0.01$ & 0.02 & $0 \cdot 10$ \\
\hline PUFA:SFA ratio & 0.413 & 0.722 & 0.303 & 0.332 & 0.07 & $<0.01$ & 0.02 & 0.06 \\
\hline \multicolumn{9}{|l|}{ Phase 3} \\
\hline SFA & $37 \cdot 7$ & 37.4 & $41 \cdot 3$ & 43.4 & 0.99 & $<0.01$ & 0.43 & 0.30 \\
\hline MUFA & $43 \cdot 7$ & $43 \cdot 7$ & $48 \cdot 9$ & $45 \cdot 5$ & 1.60 & 0.07 & 0.35 & 0.35 \\
\hline PUFA & $18 \cdot 6$ & $18 \cdot 9$ & $10 \cdot 0$ & $11 \cdot 2$ & 1.87 & $<0.01$ & 0.73 & 0.84 \\
\hline PUFA:SFA ratio & 0.454 & 0.436 & $0 \cdot 212$ & 0.268 & 0.06 & $<0.01$ & 0.72 & 0.59 \\
\hline
\end{tabular}

GB diet, Chinese conventional diet; NRC, National Research Council diet.

${ }^{*} \mathrm{SFA}=14: 0+16: 0+18: 0+20: 0$.

†MUFA $=16: 1+18: 1$.

‡PUFA $=18: 2+18: 3+20: 4+20: 5+22: 6$

\section{Discussion}

The results of the present study indicated important effects of breed type on back fat thickness, total fat percentage of carcass, and IMF of the LD and BF muscles. Landrace pigs had less fat and lower IMF than Bama mini-pigs. These findings were, indeed, expected since the aims of genetic selection in pigs, for many years, have been to increase protein growth rate and reduce fat content. Fast-growing genotypes, with a high capacity for muscle protein accretion, such as Landrace pigs, can utilise high-protein and high-energy diets without accumulating excessive amounts of fat (data not shown; YY Liu, XF Kong, FN Li and YL Lin, unpublished results). Moreover, Landrace pigs fed the GB diets containing low levels of energy and protein exerted a higher muscle mass percentage, and a lower fat percentage in the growing phase (Fig. 1). Additionally, the IMF content of Bama mini-pigs was high $(5.85 \%)$ and beyond the desired percentage (Fig. 2).
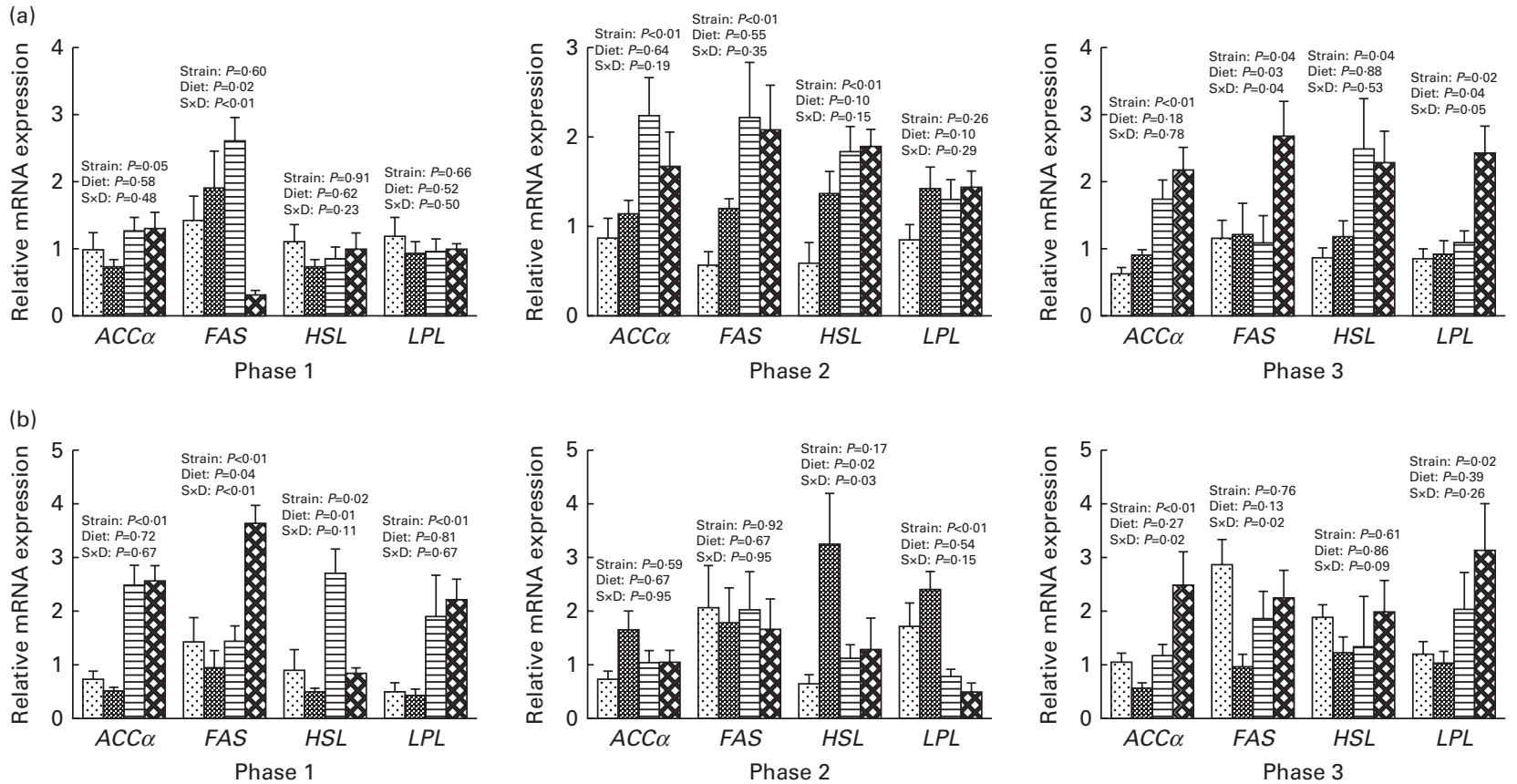

Fig. 3. Relative mRNA levels of key regulatory enzymes for fat metabolic-related genes in the longissimus dorsi (a) and biceps femoris (b) muscles of growingfinishing pigs. The mRNA expression levels of acetyl-CoA carboxylase $\alpha(A C C \alpha)$, fatty acid synthase (FAS), hormone sensitive lipase (HSL), and lipoprotein lipase $(L P L)$ were normalised using glyceraldehyde-3-phosphate dehydrogenase as an internal control. \$, Landrace pig/Chinese conventional (GB) diet group; $⿴$, Landrace pig/National Research Council (NRC) diet group; $\boxminus$, Bama mini-pig/GB diet group; Bama mini-pig/NRC diet group. Values are means ( $n$ 8), with their standard errors represented by vertical bars. Effects were considered statistically significant if $P<0.05$. $S \times D$, strain $\times$ diet interaction. 

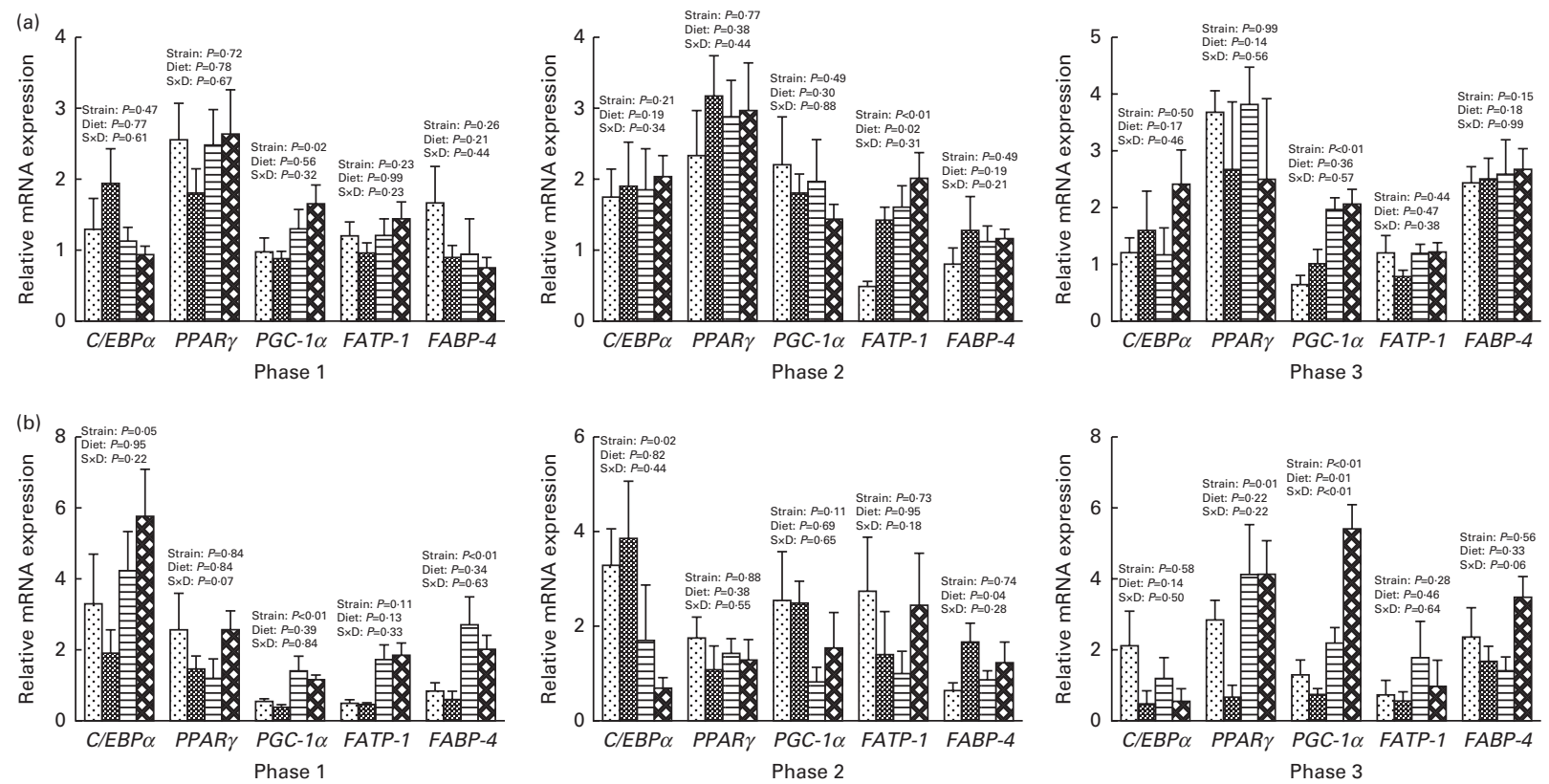

Fig. 4. Relative mRNA levels of fatty acid transport proteins for fat metabolic-related genes in the longissimus dorsi (a) and biceps femoris (b) muscles of growing-finishing pigs. The mRNA expression levels of CCAAT/enhancer-binding protein $\alpha(C / E B P \alpha)$, PPAR $\gamma$, PPAR $\gamma$ coactivator-1 (PGC-1 $\alpha)$, fatty acid transport protein 1 (FATP-1), and fatty acid-binding protein 4 (FABP-4) were normalised using glyceraldehyde-3-phosphate dehydrogenase as an internal control. race pig/Chinese conventional (GB) diet group; 图, Landrace pig/National Research Council (NRC) diet group; $\boxminus$, Bama mini-pig/GB diet group; Bama mini-pig/NRC diet group. Values are means $(n 8)$, with their standard errors represented by vertical bars. Effects were considered statistically significant if $P<0.05 . S \times D$, strain $\times$ diet interaction.

This suggested that the proper reduction in the dietary levels of energy and protein would be good for pig production.

Changes in blood total cholesterol and TAG contents can reflect dynamic lipid absorption and nutritional status in animals. Previous research has shown that the total cholesterol level is positively associated with body fat deposition ${ }^{(35)}$ and the incidence of CHD. LDL is the main carrier of total cholesterol, which is an important index to reflect excessive deposition of total cholesterol in the body. As reviewed by Anderson \& $\mathrm{Konz}^{(36)}$, a $1 \%$ increase in either total or LDLcholesterol increases the risk for CHD by $2-3 \%$, whereas the HDL content can be representative of total cholesterol clearance. In the present study, plasma levels of LDL and lipase in Bama mini-pigs were higher than those in Landrace pigs in the nursery phase, implying that the rate of fat synthesis was much greater than that of fat catabolism in Bama mini-pigs. In contrast, total cholesterol and TAG in Landrace pigs fed the NRC diet were lesser than those in pigs fed the GB diet, which reflects, to some extent, a better health condition of Landrace pigs than of Bama mini-pigs. The present results support the notion that both genes and dietary protein intake affect lipid metabolism in animals.

FA in the pig's carcass comes from two sources. Some FA, such as SFA and MUFA, are synthesised by the pig, whereas others, especially PUFA, are obtained from the diet and deposited unchanged in the tissues. In the present study, the percentages of SFA and MUFA in Bama mini-pigs were higher than those in Landrace pigs, indicating that Bama mini-pigs had a better ability of FA synthesis. FA composition influences the oxidative stability of muscle, which, in turn, affects flavour and odour of the muscle. A growing body of evidence shows ${ }^{(8)}$ that there is a high correlation between FA composition and pork tenderness, juiciness and flavour. Unsaturated FA is not only an important precursor substance of meat aroma, but also has a close relationship with the nutritional value of meat. There is a negative correlation between PUFA and meat flavour or overall acceptability, and a positive correlation between MUFA and meat flavour or overall acceptability ${ }^{(37)}$. However, PUFA content is related to the nutritional value of meat ${ }^{(2)}$. The proportion of linoleic acid $(18: 2 n-6)$ in the muscle declines as fat deposition proceeds, which is an index of fatness ${ }^{(8)}$. In the present study, the $18: 2$ content of Bama mini-pigs was lower than that of Landrace pigs, especially during the growing and finishing phases (data not shown), indicating that Bama mini-pigs had greater fat deposition. These findings are in accordance with the carcass characteristic data from the present study. Landrace pigs fed the NRC diet exhibited higher PUFA content, compared with those fed the GB diet. We suggest that the high levels of energy and protein in the diet can enhance the synthetic capacity of PUFA in swine.

Lipogenesis and lipolysis are major factors affecting adipose accumulation in tissues. At present, a few candidate genes associated with meat quality have been identified, including genes related to IMF, such as PPAR $\gamma$ and $P G C-1 \alpha$. The ACC and FAS are key regulatory enzymes in FA synthesis ${ }^{(38,39)}$. ACC $\alpha$ (the major form of ACC) is a rate-limiting enzyme in long-chain FA de novo synthesis ${ }^{(40)}$. ACC catalyses acetylCoA to malonyl-CoA in the first step reaction of FA synthesis, and FAS catalyses acetyl-CoA and malonyl-CoA to long-chain $\mathrm{FA}^{(41)}$. Therefore, ACC $\alpha$ and FAS can modulate fat deposition in animals by regulating FA synthesis. Partitioning of FA 
between TAG storage in the white adipose tissue and oxidation in the skeletal muscle can be modulated by LPL, which functions as a "metabolic gatekeeper" (42). LPL, as a rate-limiting enzyme in the metabolism of TAG, catalyses the hydrolysis of TAG in chylomicrons and VLDL, to FA. TAG hydrolysis in adipose tissue is also catalysed by $\mathrm{HSL}^{(43)}$. In the present study, the mRNA levels of both ACC $\alpha$ and $L P L$ were up-regulated substantially in Bama mini-pigs than those in Landrace pigs. This may contribute to a superior capability of FA synthesis in the white adipose tissue of Bama mini-pigs. Furthermore, the expression of $A C C \alpha$ and $P G C-1 \alpha$ was enhanced in the $\mathrm{BF}$ muscle of Bama mini-pigs fed the NRC diet, compared with those fed the GB diet in phase 3, which resulted in higher IMF deposition in Bama mini-pigs. Interestingly, Bama mini-pigs fed the GB diet had a higher mRNA level of HSL, but a lower mRNA level of FAS in the $\mathrm{BF}$ muscle during phase 1, when compared with those fed the NRC diet, but no difference was detected in other growth phases. We surmise that, during the initial growing period, the anabolism and catabolism of lipids were both stimulated in the BF muscle of Bama mini-pigs fed the NRC diet, containing high levels of energy and protein, although the IMF content of Bama mini-pigs fed the GB diet was higher than that of those fed the NRC diet.

Overall, three groups of putative FATP have been identified and characterised ${ }^{(44)}$ : (1) FA translocase; (2) plasma membrane FABP; (3) the family of FATP. The transport of FA into many tissues occurs via a protein-mediated mechanism ${ }^{(45)}$, and FATP, which is expressed in a tissue-specific pattern, plays an important role in FA transport ${ }^{(46)}$. Fasting increases FATP-1 expression in the mouse adipose tissue, whereas refeeding restores the basal level of this gene ${ }^{(47)}$, indicating that the nutritional status modulates FATP-1 expression in vivo. In the present study, the mRNA level of FATP-1 was up-regulated markedly in Bama mini-pigs than in Landrace pigs during the nursery phase, which might contribute to its stronger elevation in FA uptake and lipogenesis in the tissue at an early stage. Interestingly, we found that Landrace pigs fed the NRC diet had higher mRNA levels of FATP-1 and $F A B P-4$ in the skeletal muscle during the growing period, demonstrating a higher capacity for the transport of longchain FA (Table 5). This may help explain the balance between lipid anabolic and catabolic pathways in myofibres, as well as energy metabolism in intramuscular adipocytes.

In conclusion, the present study showed that dietary levels of protein regulated lipid anabolism and catabolism via modulating the mRNA levels of key regulatory enzymes and FATP in different muscle tissues of Bama mini-pigs (fatty genotype) and Landrace pigs (lean genotype). The effects were also reflected in the plasma concentrations of metabolites and carcass characteristics. Proper reduction of the dietary levels of protein and energy may be beneficial for pig production. These results suggest that dietary protein intake affects the expression of genes involved in lipid metabolism in the porcine skeletal muscle in a genotype-dependent manner. It provides not only a molecular mechanism, but also has important implications for developing novel dietary strategies in pig production.

\section{Supplementary material}

To view supplementary material for this article, please visit http://dx.doi.org/10.1017/S0007114514004310

\section{Acknowledgements}

The present study was jointly supported by grants from the National Basic Research Program of China (no. 2012CB124704 and 2013CB127305), the National Nature Science Foundation of China (31372325), the K.C. Wong Education Foundation (Hong Kong), and the Texas A\&M AgriLife Research. The funding agencies had no role in the design and analysis of the study or in the writing of this article.

The authors' contributions are as follows: X. K. and Y. Y. conceived and designed the study; Y. L. and F. L. conducted the animal trial, analysed and interpreted the data and wrote the paper; B. T. and G. W. revised the manuscript; L. H. and Y. L. performed the chemical analyses; J. D., Y. L. and M. G. assisted with tissue collection. All authors read and approved the final version of the manuscript.

The authors declare that there is no conflict of interest.

\section{References}

1. Wu GY (2013) Functional amino acids in nutrition and health. Amino Acids 45, 407-411.

2. Duan Y, Li FN, Li LL, et al. (2014) n-6:n-3 PUFA ratio is involved in regulating lipid metabolism and inflammation in pigs. Br J Nutr 111, 445-451.

3. Li FN, Duan YF, Li YF, et al. (2015) Effects of dietary $n-6: n-3$ PUFA ratio on fatty acid composition, free amino acid profile and gene expression of transporters in finishing pigs. $\mathrm{Br} \mathrm{J}$ Nutr (In the Press).

4. Wood JD, Nute GR, Richardson RI, et al. (2004) Effects of breed, diet and muscle on fat deposition and eating quality in pigs. Meat Sci 67, 651-667.

5. Wu GY, Fanzo J, Miller DD, et al. (2014) Production and supply of high-quality food protein for human consumption: sustainability, challenges and innovations. Ann N Y Acad Sci 1, 1-19.

6. Blanchard PJ, Ellis M, Warkup CC, et al. (1999) The influence of rate of lean and fat tissue development on pork eating quality. Anim Sci 68, 477-485.

7. Yang HS \& Yin YL (2012) Soy isoflavones modulate adipokines and myokines to regulate lipid metabolism in adipose tissue, skeletal muscle and liver of male Huanjiang mini-pigs. Molec Cell Endocrinol 365, 44-51.

8. Wood JD, Enser M, Fisher AV, et al. (2008) Fat deposition, fatty acid composition and meat quality: a review. Meat Sci $\mathbf{7 8}, 343-358$

9. Li FN, Yang HS, Duan Y, et al. (2011) Myostatin regulates preadipocyte differentiation and lipid metabolism of adipocyte via ERK1/2. Cell Biol Int 35, 1141-1146.

10. Li FN, Li LL \& Yang Y (2011) Regulation of soy isoflavones on weight gain and fat percentage: evaluation in a Chinese minipig model. Animal 5, 1903-1908.

11. Mathis N, Feidt C \& Brun-Bellut J (2003) Influence of protein/energy ratio on carcass quality during the growing period of Eurasian perch (Perca fluviatilis). Aquaculture 217, 453-464.

12. Noakes M, Keogh JB, Foster PR, et al. (2005) Effect of an energy-restricted, high-protein, low-fat diet relative to a 
conventional high-carbohydrate, low-fat diet on weight loss, body composition, nutritional status, and markers of cardiovascular health in obese women. Am J Clin Nutr 81, 1298-1306.

13. Barea R, Nieto R \& Aguilera JF (2007) Effects of the dietary protein content and the feeding level on protein and energy metabolism in Iberian pigs growing from 50 to $100 \mathrm{~kg}$ body weight. Animal 1, 357-365.

14. Teye GA, Sheard PR, Whittington FM, et al. (2006) Influence of dietary oils and protein level on pork quality. 1. Effects on muscle fatty acid composition, carcass, meat and eating quality. Meat Sci 73, 157-165.

15. Kawaguchi H, Miyoshi N, Miura N, et al. (2011) Microminipig, a non-rodent experimental animal optimized for life science research: novel atherosclerosis model induced by high fat and cholesterol diet. J Pharmacol Sci 115, 115-121.

16. Yang HS, Fu FZ, Shao H, et al. (2012) Impacts of birth weight on plasma, liver and skeletal muscle neutral amino acid profiles and intestinal amino acid transporters in suckling Huanjiang mini-piglets. PLOS ONE 7, e50921.

17. National Research Council (NRC) (2012) Nutrient Requirements of Swine. Washington, DC: National Academy Press.

18. Ministry of Agriculture of the People's Republic of China (2004) Feeding Standard of Swine (GB, NY/T 65-2004). Beijing: China Agriculture Press.

19. Yin J, Ren WK, Duan J, et al. (2014) Dietary arginine supplementation enhances intestinal expression of SLC7A7 and SLC7A1 and ameliorates growth depression in mycotoxinchallenged pigs. Amino Acids 46, 883-892.

20. Kong XF, Wu GY, Liao YP, et al. (2007) Dietary supplementation with Chinese herbal ultra-fine powder enhances cellular and humoral immunity in early-weaned piglets. Livest Sci 108, 94-98.

21. Yin FG, Liu YL, Yin YL, et al. (2009) Dietary supplementation with Astragalus polysaccharide enhances ileal digestibilities and serum concentrations of amino acids in early weaned piglets. Amino Acids 37, 263-270.

22. Zhou XL, Kong XF, Lian GQ, et al. (2014) Dietary supplementation with soybean oligosaccharides increases short-chain fatty acids but decreases protein-derived catabolites in the intestinal luminal content of weaned Huanjiang mini-piglets. Nutr Res 34, 780-788.

23. Kang P, Zhang L, Hou Y, et al. (2014) Effects of L-proline on the growth performance, and blood parameters in weaned lipopolysaccharide (CPS)-challenged pigs. Asian-Aust J Anim Sci 27, 1150-1156.

24. Ren WK, Yin J, Wu MM, et al. (2014) Effects of L-arginine or L-glutamine supplementation in dextran sulfate sodium colitis. PLOS ONE 9, e88335.

25. Feng ZM, Zhou XL, Wu F, et al. (2014) Both dietary supplementation with monosodium L-glutamate and fat modify circulating and tissue amino acid pools in growing pigs, but with little interactive effect. PLOS ONE 9, e84533.

26. Ministry of Agriculture of the People's Republic of China (1987) Performance Measurement Technology Regulations for Chinese Lean Pig. Beijing: China Standard Press.

27. Cunniff P (editor) (1997) Official Methods of Analysis of AOAC (Association of Official Analytical Chemists) International, 16th ed. Gaithersburg, MD: AOAC.

28. Tan B, Yin YL, Liu ZQ, et al. (2009) Dietary L-arginine supplementation increases muscle gain and reduces body fat mass in growing-finishing pigs. Amino Acids 37, 169-175.

29. Yin YL, McEvoy J, Souffrant WB, et al. (2000) Apparent digestibility (ileal and overall) of nutrients and endogenous nitrogen losses in growing pigs fed wheat or wheat by- products without or with xylanase supplementation. Livest Prod Sci 62, 119-132.

30. Wu X, Ruan Z, Gao YL, et al. (2010) Dietary supplementation with L-arginine or $N$-carbamylglutamate enhances intestinal growth and heat shock protein-70 expression in weanling pigs fed a corn- and soybean meal-based diet. Amino Acids 39, 831-839.

31. Wang W, Blachier F, Fu D, et al. (2013) Ontogenic expression of the amino acid transporter b0,1AT in suckling Huanjiang piglets: effect of intra-uterine growth restriction. $\mathrm{Br} \mathrm{J} \mathrm{Nutr}$ 110, 823-830.

32. Liu XD, Wu X, Yin YL, et al. (2012) Effects of dietary L-arginine or $\mathrm{N}$-carbamylglutamate supplementation during late gestation of sows on the miR-15b/16, miR-221/222, VEGFA and eNOS expression in umbilical vein. Amino Acids $\mathbf{4 2}$, 2111-2119.

33. Bustin SA, Benes V, Garson JA, et al. (2009) The MIQE guidelines: minimum information for publication of quantitative real-time PCR experiments. Clin Chem 55, 611-622.

34. Wang W, Shi CY, Zhang JS, et al. (2009) Molecular cloning, distribution and ontogenetic expression of the oligopeptide transporter PepT1 mRNA in Tibetan suckling piglets. Amino Acids 37, 593-601.

35. Sink JD, Wilson LL, McCarthy RD, et al. (1973) Interrelationships between serum-lipids, energy intake, milk-production, growth and body characteristics in Angus-Holstein cows and their progeny. I Anim Sci 36, 313-317.

36. Anderson JW \& Konz EC (2001) Obesity and disease management: effects of weight loss on comorbid conditions. Obes Res 9, 326S-334S.

37. Cameron ND, Enser M, Nute GR, et al. (2000) Genotype with nutrition interaction on fatty acid composition of intramuscular fat and the relationship with flavour of pig meat. Meat Sci 55, 187-195.

38. Munday MR (2002) Regulation of mammalian acetyl-CoA carboxylase. Biochem Soc Trans 30, 1059-1064.

39. Chen J, Yang XJ, Tong H, et al. (2004) Expressions of FAS and HSL mRNA in longissimus dorsi muscle and their relation to intramuscular fat contents in pig. J Agric Biotechnol 12, 422-426.

40. Tan B, Yin YL, Liu ZQ, et al. (2011) Dietary L-arginine supplementation differentially regulates expression of lipid-metabolic genes in porcine adipose tissue and skeletal muscle. J Nutr Biochem 22, 441-445.

41. Loftus TM, Jaworsky DE, Frehywot GL, et al. (2000) Reduced food intake and body weight in mice treated with fatty acid synthase inhibitors. Science 288, 2379-2381.

42. Zechner R (1997) The tissue-specific expression of lipoprotein lipase: implications for energy and lipoprotein metabolism. Curr Opin Lipidol 8, 77-88.

43. Zou CH \& Shao JH (2008) Role of adipocytokines in obesityassociated insulin resistance. J Nutr Biochem 19, 277-286.

44. Binnert C, Koistinen HA, Martin GV, et al. (2000) Fatty acid transport protein-1 mRNA expression in skeletal muscle and in adipose tissue in humans. Am J Physiol Endocrinol Metab 279, E1072-E1079.

45. Bonen A, Chabowski A, Luiken J, et al. (2007) Mechanisms and regulation of protein-mediated cellular fatty acid uptake: molecular, biochemical, and physiological evidence. Physiology 22, 15-29.

46. DiRusso CC, Li H, Darwis D, et al. (2005) Comparative biochemical studies of the murine fatty acid transport proteins (FATP) expressed in yeast. J Biol Chem 280, 16829-16837.

47. Man MZ, Hui TY, Schaffer JE, et al. (1996) Regulation of the murine adipocyte fatty acid transporter gene by insulin. $\mathrm{Mol}$ Endocrinol 10, 1021-1028. 